\title{
A physical rehabilitation program with a methodical basis and what it means for young athletes with mild myopia and spasm of accommodation
}

\author{
Efim Shmakov, Kozyreva Olga Vladimirovna \\ Russian State University of Physical Education, Sport, Youth and Tourism (SCOLIPE), Chair of Physical Rehabilitation and Physical Culture, \\ Moscow, Russia
}

\section{Email address:}

efimshmakov@ymail.com (E.Shmakov)

\section{To cite this article:}

Efim Shmakov, Kozyreva Olga Vladimirovna. A Physical Rehabilitation Program with a Methodical Basis and what it Means for Young Athletes with Mild Myopia and Spasm of Accommodation. American Journal of Life Sciences. Special Issue: Marine Biology.

Vol. 3, No. 1-1, 2015, pp. 1-5. doi: 10.11648/j.ajls.s.2015030101.11

\begin{abstract}
The aim of this well-thought and complex physical rehabilitation program is to expand the body-motor activity of young athletes with mild myopia. It increases one's body-resistance to external conditions. It enhances the way the bodilyorgans and the whole body function. It has been found out that students with myopia are lagging behind in physical and motor development in comparison with healthy students. This study is about the characteristics of training and education of children with myopia, mainly school age or preschool children, and also young athletes with visual impairments, particularly school children who have mild myopia. Research and practice have confirmed that an improved condition of the health of students, who participated at this coaching program, took place most successfully, if the lessons were conducted by a complex method, and when there were used a variety of means. In this regard, there is reason to believe that the process of normalization and correction of physical development of students with visual impairment is possible through a complex interaction of various means of physical rehabilitation, according to how these are matched to the peculiarities of health, visual impairment, physical development, physical fitness and projected future professional activities of individual school children. The content and duration of class-time was rigorously determined, when this physical rehabilitation program was conducted. It was understood that the basis of a sequential process of physical rehabilitation is a systematic and a continuous operation, if was expected a strengthening and improvement of the functionality of the growing body of a school child. To achieve this, it had to include a comprehensive physical rehabilitation program for children from 8 to 15 years, with mild myopia and spasm of accommodation. This comprehensive program of physical rehabilitation includes the following components. 1. Physiotherapy sessions, which consist of general developmental and special exercises with different gym-gear and fitness equipment. 2.Recreational and educational games; 3.Breathing exercises; 4. Relaxation exercises; 5.Do-it-yourself eye-massage techniques; 6. Do-it-yourself special physical exercises.
\end{abstract}

Keywords: Physical Rehabilitation, Physical Therapy Technique, General Developmental and Special Exercises, Myopia, Young Athletes

\section{Introduction}

According to Russia's Government Statistics, for the period from 2001 to 2012 the number of students with low vision in Russia has increased from 11.01 to 15.8 cases per 1000 students examined, as it was reported by the author A.L. Repin in 2013, who not only significantly updated the work on prevention and correction of visual impairment, but also corrected abnormalities in the physical state of this generation of young people. As stated by many authors, such as L. V. Shapkova in 2003, or by I.A Akhmadullina in 2011, by Czepita D., by Lodygowska E., by Czepita M., in 2008, and by others, school children with myopia are lagging behind in physical and body-motor development, compared to healthy students.

Currently studied are the characteristics of how to train and educate children with myopia, mainly school age and preschool children, and also athletes with visual impairments, particularly with mild myopia [2, 6, 7]. However, the study 
of the situation of physical development and the process of its correction at young athletes with myopia requires a close attention from specialists.

Intensive workload has a negative effect on the central nervous system of students with myopia, which leads to the deterioration of their visual analyzer.

Research done by I.A, Ahmadullina in 2011, or by J.J. Walline, or by K. Lindsley, or by SS Vedula, or by SA Cotter, or by D,O. Mutti, or by J.D. Twelker in 2011, as well as practice, have confirmed that the condition of school children improved most successfully if the lessons were conducted by a complex method, and when there were used a variety of means. In this regard, there is reason to believe that the process of normalization and correction of physical development of students with visual impairment is possible through a complex interaction of various means of physical rehabilitation, according to how these are applied to the peculiarities of health, visual impairment, physical development, physical fitness and future projectedprofessional activities of the school children from the new generation. [2, 6, 9].Many researchers, who include S.P. Yevseyev, A.A. Potapchuk, S.V. Matveev, M.D. Didur, K.A. Rose, I.G. Morgan, J Ip, A Kifley, S. Huynh, W. Smith, P. Mitchell, and others, believe that physical rehabilitation is a priority, as it allows to influence various aspects of a school child's personality development, including physical.

Nevertheless, the potential for a physical cure in the process of rehabilitation of young athletes with myopia is not used in full at the moment $[4,8]$.The problem is, that a set of tools for improving points of reference is not clearly defined. The impact of these resources, regarding physical improvement of the functional condition of school children's eyes, is studied very little, in relation to this generation of children.

This inconsistency is resolved by introducing the integrated program of physical rehabilitation, which involves the use of a complex physical education approach, and is carried out by improving the recreational time of school children.

It is inspired from the generally accepted pedagogical principles, governing the content, methods and forms of organizing school classes, through improving methodological foundations concerning physical rehabilitation program for young athletes.

The main point of this well-thought and complex physical rehabilitation program is to expand the body-motor activity of young athletes with mild myopia. It increases the body's resistance to external conditions. It enhances the way the organs and the whole body function.

When this physical rehabilitation program was implemented,

It was decided the content and duration of class periods.

It was understood that the basis of a sequential process of physical rehabilitation is a systematic and a continuous procedure, done in order to strengthen and improve the functionality of a growing body. To achieve these, a comprehensive physical rehabilitation program was implemented for children from 8 to 15 years, who have mild myopia and spasm of accommodation.

This comprehensive program of physical rehabilitation included the following components:

1. Physiotherapy sessions, which have general developmental and special exercises with different gym-gear and fitness equipment.

2. Recreational and educational games, breathing exercises, relaxation exercises.

3. Do-it-yourself eye massage techniques,

4. Do-it-yourself special physical exercises.

Traditionally, each physiotherapy lesson has consisted of three parts.

Chapeau has included exercises to swing and relax. E.S. Avetisov had used accommodation and training extraocular muscles. K.A. Matz has adapted sports' games, and has introduced playing exercises. S.V. Bondarenko came up with special visual games, and with general developmental special exercises. The main part consisted of exercises to train the body strength endurance of one's body muscles. N.I. Burmistrov introduced exercises for body posture correction, of cases of improper posture. This author also introduced elements of other sports, for example of skiing, running, jumping, sliding and doing sports games.

The final part consists of breathing exercises, general developmental exercises, and dynamic exercises for the muscles of the eye.

This program duration is 9 months. It includes the following parts.

1. Warm up,

2. Train by doing exercises,

3. Cool down.

The following general developmental exercises are employed in the warm up time.

1. Exercises for all muscle groups in different starting positions.

2. Basic exercise movements, such as walk and observe options, easy run, jump, climb, crawl, and throw weights.

3. Dynamic relaxation exercises.

4. Training extra-ocular muscles as taught by E.S. Avetisov and K.A. Matz, which make up $25 \%$ of all classes.

Special exercises are used to build the muscles of the upper body and the abdominal muscles, in different working positions, such as laying face down, or standing, breathing exercises such as chest and diaphragmatic breathing.

In this time, were used elements of sports and playing exercises, especially visual games proposed by S.V. Bondarenko.

The procedures were in this manner:

1. The training process lasts for about 20-25 minutes every day.

2. The students have a break of 10 to 20 minutes between workouts, every day.

3. There is a cooling down time of 20 minutes after training. 
4. There is a period of 6 weeks for the students to adapt to this 9 months program.

During the training time, the main task is to keep an eye on how the exercises are done, and make improvements as the classes went ahead.

Throughout the training period, it was made sure to increase the number of repetitions of exercises. To the total load it was added the complexity and diversity of the artistic exercises.

Forms of physical rehabilitation at this stage:

1. Doing exercises to train the endurance and strength of the body muscles.

2. Doing exercises to correct posture, at school children with poor posture, as proposed by N.I. Burmistrov.

3. Doing elements of other sports, such as body movement while skiing, running, jumping, sliding, or performing sports games.

From the special exercises performed, there were breathing exercises and elements of other sports such as skiing, running, and jumping.

There were also outdoors ball games or other games, which used power to move objects without contact with an opponent.

Then there were volleyball, tennis and table tennis, badminton, baseball, skittles, bowling, golf, cricket, snooker, throwing rings, and throwing a ball at a target.

The ratio, between specific exercises, and general developmental exercises was 2 to 1 .

Things were organized as follows:

1. The training class lasted for 20 to 25 minutes every day.

2. There were breaks from 10 to 20 minutes between the workouts every day.

3. There was a cool down period after training, for the duration of about 20 to 25 minutes.

The duration of the training period was 24 weeks.

The program at this time has excluded therapeutic massage. Otherwise the content and structure of the program would be the same as the warm up time.

The stabilizing period is a time, in which the main task is to practice and learn the exercises and memorize the sequence of the exercises, while maintaining the achieved level of physical fitness and skills to do-it-yourself exercise.

The characteristic feature of this period is to complete physical rehabilitation program, and continue to train independently. The duration of sessions is reduced on average by 5 to 7 minutes. The number of repetitions and special exercises are done on average 2 to 4 times a day.

The adjustment period takes 8 weeks. The content and structure of this time is similar to adaptation period.

From the exercises, which are performed at this stage, there are the general developmental exercises. From the special exercises there are breathing exercises. The ratio between specific and general developmental exercises is 1 to 3.

Things were organized as follows:

1. During the training course, the time of training was about 20 to 25 minutes every day.
2. The break between workouts was 10 to 20 minutes every day.

It should be noted that a technique of physical therapy for the young athletes was used, depending on the particular sport.

\section{Methods}

In the general physical preparation domain, the following means of physical training were used to strengthen muscles and harmoniously develop swimmer skills:

1. RPT applied exercises, such as climb up a rope, a pole, or climb up a wall, jump and throw a ball, jump over natural obstacles on the ground, and carry a workout partner.

2. General developmental exercise sports, swimmer auxiliary gym, which include single and paired exercises without a theme; exercises with padded balls weighing from $2 \mathrm{~kg}$ to $5 \mathrm{~kg}$, dumbbells weighing 3 to 8 $\mathrm{kg}$, rubber shock absorber, and gymnastics sticks.

3. Elements of other sports, such as the body movement while skiing, running, jumping, sliding and doing sports games.

\section{Materials}

Strength training exercises on the ground have been created with regard to the shape and structure of the outer movements of the swimmer in the water.

Compliance with the amplitude and direction of the force of movements and kicking torso has been achieved as a relatively rational choice for this target, given the direction of the athlete's applied efforts.

Young swimmers have used exercises for the muscles of the shoulder, waist and hands, with a lightweight rod, which weighs 10 to 15 kilograms.

Part gymnastics exercises, for children wanting to do athletics, were held at the gym.

The warm-up exercises as a general developmental (10 '), and certain special exercises (20-25'), as well as playing with the gym-gear such as balls, and hoops were automatically included in the program.

All exercises in the gym were performed to the rhythm of music with a tempo of $80-100$ beats per minute.

This program requires the use of exercise to ascertain and improve the body-motor skills, and the development of one's physical qualities.

Breathing exercises, corrective exercises, and developmental exercises, without a theme were used. Exercise gear, such as dumbbells from 0.5 to 2 kilograms, padded balls from 1 to 2 kilograms, hoops and other equipment were also use. The workload while doing exercises was increased by raising the number of repetitions.

Also, a set of exercises has supplemented the well being of the participants while doing variable games and special exercises for the eyes.

Part gymnastics exercises for children, who were engaged 
in freestyle wrestling, were held at the gym.

\section{Results}

Myopia is inherited from the parents. People affected are mainly young. This ailment strikes during the school years, while students learn at the secondary and higher educational institutions. It is associated with sustained visual activity at close range such as reading, writing, or drawing, especially in the wrong lighting and poor hygienic conditions. Thus, according to different authors, myopia among schoolchildren ranges from $2.3 \%$ to $16.2 \%$, and it may even be as high as $31 \%$. This percentage is even higher at university students, according to E.V. Gurova, 2007.

As stated, the myopia often occurs in children and adults with poor physical development, with shortcomings in their general state of health. Insufficient volume of general motor activity at schoolchildren, and a high visual load may contribute to the development of myopia. This limits one's ability to get to adulthood, without changes to his or her vocational guidance and quality of life. Health complications could also arise. Myopia is a predisposing factor for retinal detachment, retinopathy, glaucoma, and therefore it contributes to the decrease in visual acuity, and to blindness.

All this testifies to the lack of effectiveness of the treatment and rehabilitation measures for the restoration of impaired vision in myopia progression of myopia with age, the appearance of severe complications such as retinal detachment, etc.

Therefore, some authors suggest that the need to intensify coming up with methods for the prevention of visual impairment, such as myopia, or conducting medical, occupational and physical rehabilitation, as well as ensuring effective social adaptation for the children, who are with an institution, and to look carefully at the relationship between doctors, teachers, psychologists, social workers and the child's family (V.G. Kovylina, 2008).

\section{Discussion}

When we make available a methodological framework of a program of physical rehabilitation for young athletes, we proceeded from the following common pedagogical principles governing the content, methods and forms of organization (V.N. Platonov, 1969 Y.F. Udalov, 1988):

A. The principle of harmony between health, educational, and developmental problems;

B. The principle of consciousness and activity such as educating children to master meaningful exercise, and also to motivate them and instill in them a desire to correctly perform a proposed task;

C. The principle of availability, such as when students are being assigned with tasks, these should match their powers and abilities. Tasks assigned to preschool children should not contain exercises of static strength, and when one assigns an exercise program, should take into account the individual characteristics of each child.
D. The principle of being systematic such as having regularity and a gradually defined load.

E. The principle of strength such as applying certain phasing and a sufficient number of repetitions.

F. The principle of clarity.

G. The principle of personal example;

While we put together physical rehabilitation programs, and we assign class breaks and their duration, we assume that at the basis of a sequential process of physical rehabilitation and the subsequent development of functional capacity of the organism is a systematic continuous training work.

To achieve this, it has been developed a comprehensive physical rehabilitation program for children 6-15 years old with mild myopia and spasm of accommodation. A comprehensive physical rehabilitation program includes the following activities:

1. Physiotherapy such as general developmental and special exercises with various equipment, outdoor games adapted, specialized visual games, breathing exercises, relaxation exercises;

2. Do-it-yourself massage techniques for the eye;

3. Do-it-yourself special physical exercises.

Comprehensive physical rehabilitation program for young athletes with mild myopia consists of 3 parts.

The first part include:

1.a. Exercises for the "swing" and "relaxation" of accommodation and training external eye muscles, first introduced by E.S. Avetisov and K.A. Matz;

1.b. Adapted sports games and exercises;

1.c. Special visual games first introduced by S.V. Bondarenko.

The second part include:

2.a. Exercises to train the static strength endurance muscles of the body;

2.b. Exercises for correction of posture disorders in N.I. Burmistrova;

2.c. Elements of other sports (eg movement of skiing, running, jumping, sliding and sports games).

3. The third part include:

3.a. Breathing exercises

3.b. Doing, general developmental exercises, and also doing other exercises.

A complex technique was carried out into six major forms of physical education such as do-it-yourself exercises one likes, or doing an hour of dynamic exercise, and of morning pure gymnastics, or doing, therapeutic massage.

Therefore, the prevalence of myopia in adolescents, who have greater visual load, increases with time, the severity of clinical manifestations and the restrictions it imposes on one's social activity, demonstrates the relevance of this problem and the need for further development of sciencebased restoration activities that require both new approaches and an integrated use of physical rehabilitation means.

Thus, the developed physical rehabilitation program for young athletes with mild myopia has included methods and especially principles, directions on diagnostic, sports and 
recreation, improvement recreation, be it vocational or applied. This program has three parts, and a description of their contents.

This physical rehabilitation program is applied at school through many forms of physical education, during school hours.

\section{Conclusions}

This program was designed for the comprehensive use of specific exercise, such as different types of exercises, and non-specific tasks, such as ophthalmologic training, do-ityourself-massage, eye massage with one's palm, and other means of physical rehabilitation.

This comprehensive program of physical rehabilitation helps improve the health of school children. It also enhances their anthropometrical indexes. It expands indicators of physical fitness, physical development, and health indicators. It also increases the accommodative and refractive indices of the eyesight. It makes progress with one's mental and emotional state.

\section{References}

[1] Avetisov E.S. Myopia / Avetisov E.S, Matz K.A. - 2nd ed., Rev. and add. Moscow, 2002. - 284.

[2] I.A. Akhmadullina, Physical education of visually impaired students from a specialized secondary educational institution: Author. diss ... kand.ped.nauk. / IA Akhmadullina. Naberezhnye Chelny, 2011. - 25.

[3] Buylova L.A. Application of a game method in physical education: Author. dis ... cand. ped. Science / L.A. Buylova. Malahovka: MGAFK 2004. - 21.
[4] Evseev, S.P. Adaptive physical education / S.P. Evseev, Shapkova L.V. M.Sovetsky sport, 2000. - 238.

[5] Czepita D, Lodygowska E, Czepita M. Are children with myopia more intelligent? A literature review. / Ann Acad Med Stetin. 2008, 54 (1) :13-6.

[6] Rose KA, Morgan IG, Ip J, Kifley A, Huynh S, Smith W, Mitchell P. Outdoor activity reduces the prevalence of myopia in children. / Ophthalmology. 2008 Aug; 115 (8) :1279-85.

[7] Walline JJ, Lindsley K, Vedula SS, Cotter SA, Mutti DO, Twelker JD. Interventions to slow progression of myopia in children. / Cochrane Database Syst Rev. 2011 Dec 7, (12): CD004916.

[8] Deere K, Williams C, Leary S, Mattocks C, Ness A, Blair SN, Riddoch C. Myopia and later physical activity in adolescence: a prospective study. // Br J Sports Med. 2009 Jul;43(7):542-4. doi: $10.1136 /$ bjsm.2008.049288.

[9] Guggenheim JA, Northstone K, McMahon G, Ness AR, Deere K, Mattocks C, Pourcain BS, Williams C. Time outdoors and physical activity as predictors of incident myopia in childhood a prospective cohort study. // Invest Ophthalmol Vis Sci. 2012 May 14;53(6):2856-65.

[10] Ngo CS, Pan CW, Finkelstein EA, Lee CF, Wong IB, Ong J, Ang M, Wong TY, Saw SM. A cluster randomised controlled trial evaluating an incentive-based outdoor physical activity programme to increase outdoor time and prevent myopia in children. // Ophthalmic Physiol Opt. 2014 May;34(3):362-8.

[11] Read SA, Collins MJ, Vincent SJ. Light exposure and physical activity in myopic and emmetropic children. // Optom Vis Sci. 2014 Mar;91(3):330-41. 